\title{
EDITORIAL
}

\section{The concept of disease in psychiatry ${ }^{1}$}

Rawnsley (1984), analysing the reasons for the recent tarnishing of the psychiatrist's public image, has stated that 'first and foremost is the nature of mental disorder itself and the response this generates in society'. But what is mental disorder? Kendell (1975) opened his paper on 'The concept of disease and its implications for psychiatry' by saying: 'It has often been suggested in recent years that there is no such thing as mental illness'. How can one arrive at such a suggestion in view of the large number of people sustaining heavy losses in terms of quality of life and life expectancy attributable to various forms of mental illness and the fact that at least a certain percentage of these people finds remedy or relief in therapeutic measures? The uncertainty stems from a common source. According to such differing representatives of the mental health discipline as Schneider (1950), Eysenck (1960) and Szasz (1961), only derangements of physiological and psychological processes with an observable physical basis qualify as diseases. Deviant behaviour not associated with a physical cause was classified by Schneider as variants of normal human conduct which psychiatry should regard as its concern only in exceptional cases. Eysenck defined it as learnt behaviour and, thus, as a domain of psychology. Szasz explained such phenomena in interactional terms and opposed any intervention by the mental health profession.

This line of argument, though a product of a long tradition in medical science (Hippocrates, Cullen, Griesinger), is not conclusive. The physical and mental derangements underlying mental disorder cover only two possible areas from which illness may originate. At the mental level the problem of distinguishing between sanity and insanity cannot be solved by identifying the areas in which their possible causes might reside.

\section{IS THERE A GENERAL CONCEPT OF DISEASE IN MENTAL ILLNESS?}

Scadding (1967) compared the attempts to look for a unified concept of disease "with the grapplings of theologians with the Problem of Evil'. This analogy is too simple. As long as illnesses are described as organic changes (Virchow, 1895), deviations from the norm or derangements of physiological and psychological processes (Cohnheim, 1882), without offering any explanation as to what is understood by the constitutive criteria of being 'ill' in all these conditions, the concept of illness itself remains undefined. This means that illness in general describes more than a class containing a variety of conditions and diagnoses: "We have first to agree on an adequate definition of illness. . . before we can begin to decide that mental illnesses are legitimately so called' (Kendell, 1975).

Whatever is meant by illness needs to be distinguished from (1) health as the norm; (2) non-morbid deviations from the norm - for example, the social or legal norm (crime, absenteeism from work etc.), or the cultural norm (extreme philosophies or life-styles without relevance to health); and (3) non-pathological distress or 'common human suffering'. If necessary, illness may be further distinguished from other forms of health deficits - for example, deformities and disabilities.

\section{ILLNESS IN EVERYDAY LIFE}

From a pre-scientific point of view illness is usually experienced as distress and weakness. Distress that qualifies as illness is associated with pain, fever, depression or other adversities reducing the

\footnotetext{
1 Address for correspondence: Prof. Dr Dr H. Häfner, Central Institute of Mental Health, PO Box 5970, D-6800 Mannheim 1, FRG.
} 
person's well-being. 'Weakness' means a more or less manifest incapacity to do what one wishes or what life demands. Illness has thus something to do with a disturbance of the vital functions, but so general a criterion of illness as this is too imprecise. However, at the level of certain vital functions - such as nutrition, mobility, perception or thinking - disturbances can be described with sufficient precision. In this context, the distinction between 'ill' and 'non-ill' is related to norms and threshold values.

\section{ILLNESS IN THE SOCIAL AND NORMATIVE CONTEXT}

Illness has first of all a private dimension, like life or death, between which it is to be located. If the person affected is unaware of his own illness and his condition is only perceived by others, it also exists for the person concerned. To the same degree as the life and the death of an individual are the concern of relatives and the community at large, illness too has a social dimension.

A well-functioning community with a humanitarian orientation responds to the serious illness of its members with attempts at institutionalization. Parsons $(1951 a, b, 1958)$ has subsumed this process under the notion of the sick-role, a system of norms, privileges and obligations. In systems of social security the privileges provided by the sick-role also include financial support which, depending on its extent, also offers opportunities for misuse, e.g. gain from illness: 'For anyone who in such social systems wishes to be freed from the obligations imposed by the social role, the easiest way of achieving this is to adopt the sick-role' (Pflanz, 1969). In order to limit the misuse of the privileges provided by the sick-role, most societies have assigned physicians the task of deciding who is merely simulating and who is genuinely and sufficiently ill to be freed from social obligations and to benefit from the rewards.

Legal norms require a distinction to be made between morbid and non-morbid deviant behaviour in two comprehensive areas of life: (1) in connection with the liability for unlawful encroachments upon the rights of others (criminal responsibility); and (2) in connection with the capacity for managing one's own (mainly economic) affairs (legal competency, etc.). A constituent of the notion of illness in a legal context is the involuntary nature of the health deficit, the person's incapacity. Intentionality of or accountability for deviant behaviour distinguishes crime and other deviations from normal conduct, such as extreme ideologies or life-styles, from illness. Scientific agnosticism (Schneider, 1956) merely negates this difficult problem of drawing a line between unwillingness and illness-related incapacity. It is not in a position to offer any solution. While somatic medicine has developed several simple methods of distinguishing the two - for example, measurement of the active and passive flexibility of a diseased joint - psychiatry has often greater difficulties in distinguishing between incapacity and unwillingness. The difficulties are reflected in the low reliability of the assessment of illness-related incapacity on the basis of normative definitions in borderline cases - for example, of criminal responsibility.

Practical and forensic medicine require more or less clear-cut criteria for distinguishing between sickness and health in the context of social and legal norms. These norms are fairly stable in the central area of severe illness; at the periphery they are subject to considerable modification in the light of normative and social re-definition. The steep increase in the utilization of health services in minor depressive states and other minor mental disorders in some Western countries is probably associated with the re-definition of the 'common suffering as God's will' as disease conditions that need to be and can be treated. The consequences of a changed norm were even more precisely measurable in the case of raising the requirements of reading and writing abilities in the elementary schools of the Federal Republic of Germany in the 1970s, which led to increased case rates of learning disabilities (Häfner, 1985). These developments, which have recently been criticized by Richman \& Barry (1985) under the title 'The myth of massive psychiatric need', illustrate the relationships between the 'Zeitgeist', the changes at the periphery of the concept of disease in general, and the therapeutic need. At the same time, it is also apparent that the great mass of disappointed hopes for obtaining remedy or relief will lead to a more restricted concept of mental illness in the future.

To sum up, illness in general refers to a condition in which the individual's vital functions are 
affected. This condition is usually associated with subjective suffering and a reduced capacity of functioning in its various dimensions. The distinction from deformity or disability, which are also health deficits, is made possible by the temporal aspect of illness: as opposed to disability, illness shows a characteristic course over time, with an outcome in cure, disability or death.

The general concept of mental illness, which is needed in both everyday life and in an ordered community, needs to be rendered more concrete in various social and normative contexts. Discrepancies in applying the category 'mentally ill' are unavoidable at the periphery of the concept. Incongruities occur even between various observers and, above all, over different normative systems and cultures, explaining part of the great variation in the rates for minor psychiatric disorders in population studies or the utilization of services. If case definitions are standardized and the reliability of the assessment techniques improved, the differences become less marked. In addition, the discrimination between ill and healthy cases is often based on conventions in various epidemiological and other studies - for example, in the form of a cut-off point on a symptom scale, especially if social or biological norms are not available.

\section{SPECIFIC CONCEPTS OF MENTAL DISEASES}

The general concept of disease is neutral with respect to individual diagnoses or aetiology. It can be rendered more specific by defining individual disease concepts or other types of disorder constructs, such as illness-like crises, symptom patterns or dimensional disorder profiles. Each of these classificatory systems or taxonomies provides information on a condition requiring treatment to the person affected, his relatives and the professional workers concerned with his examination or care. In this way not only is an observed condition categorized, but also a wealth of preliminary information is provided on the course, treatment modalities and their risks, and outcome probabilities. The definition and identification of a specific disease condition constitute the basis for the investigation of its frequency and distribution and its relatedness to other physicochemical, biological, mental and social phenomena.

An ideal diagnosis is based on a homogeneous disease entity attributable to a common cause. Kraepelin's hopes of classifying characteristic psychiatric syndromes on the basis of unambiguous topological and aetiological data in natural disease entities have largely failed to materialize. Apart from the few homogeneous diseases comprising unitary and complex patterns of mental disorder, such as Down's Syndrome or general paresis, there exist a great variety of imprecisely defined disease conditions and heterogeneous syndromes whose causation is poorly understood.

How can one know whether an observed condition is a disease if its causes are unknown? Sydenham (1742) formulated the minimum requirements that satisfy our practical needs by postulating a syndrome, which consists of several intercorrelating symptoms and is sufficiently distinguishable from other symptom clusters. Furthermore, the syndrome should exhibit a stable, characteristic structure, in order to enable predictions to be made and to justify therapeutic interventions. The disease constructs of the endogeneous psychoses proposed by Kraepelin are based on such entities of syndrome and outcome. They also include regular transitions between syndromes - for example, the alternation of phases of manic and depressive syndromes in bipolar, affective psychosis.

Such disease constructs satisfy the practical and scientific requirements better when they can be objectified and measured and when their underlying pathological mechanisms can be established. This calls for the identification of quantifiable indicators or components of disease constructs and the detection of the pathological dysfunction, which render it possible to group certain overt manifestations together and to explain their course and outcome. This would increase the predictive power of the constructs and provide clues in the search for the causes.

Even in the field of disease constructs of obscure aetiology there are several effective forms of treatment which may be classified as operating somewhere between the causal and the symptomatic level - for example, the dopamine blockade in some forms of functional psychosis or the systematic desensitization of a phobia. The development of causal therapies, however, requires knowledge of 
the aetiology. This is likely to cause considerable difficulties in the treatment of several mental disorders which may be described as valid disease constructs but which are either heterogeneous or have multifactorial causation.

\section{CONCLUSIONS}

The development of disease constructs for certain mental disorders is meaningful if they provide at least an adequate explanation of the symptom clusters, the underlying pathological mechanisms and the course of the disorder. Forms of distress or deviant behaviour which can better be explained by other than disease constructs - for example, by learning or crisis models - should not be described as diseases. In the light of the general concept of disease it should then be tested whether and under which conditions a particular case of mental disorder - no matter whether it is defined as a disease construct or in some other terms - meets the criteria of the general concept of disease or its social and normative requirements.

Critics of the disease concept rightly point out that many mental disorders which are still interpreted as diseases - for example, phobias and obsessional or compulsive states - would more appropriately be explained in terms of different psychological models than those disease constructs originally developed by somatic medicine. The view that mental disorders without a physical basis are not real diseases has its origin in the conviction dating back to Descartes and Kant that only the body can become ill, whereas the psyche (the 'res cogitans' or the 'Vernunft') is free and capable of solving its problems autonomously unless affected by a physical factor. This doctrine, however, is neither logical nor useful empirically.

H. H ̈̈FNER

\section{REFERENCES}

Cohnheim, J. (1882). Vorlesungen über allgemeine Pathologie (2nd revised edn). Hirschwald: Berlin.

Eysenck, H. J. (1960). Classification and the problem of diagnosis. In Handbook of Abnormal Psychology (ed. H. J. Eysenck), pp. 1-31. Pitman Medical: London.

Häfner, H. (1985). Are mental disorders increasing over time? Psychopathology 18, 66-81.

Kendell, R. E. (1975). The concept of disease and its implications for psychiatry. British Journal of Psychiatry 127, 305-315.

Parsons, T. (1951 a). The Social System. Free Press: Glencoe, Ill.

Parsons, T. $(1951 b)$. Illness and the role of the physician: a sociological perspective. American Journal of Orthopsychiatry 21, 452-460.

Parsons, T. (1958). Struktur und Funktion der modernen Medizin. In Probleme der Medizinsoziologie (ed. R. König, M. Tönnesmann), pp. 10-57. Kölner Zeitschrift für Soziologie, Special Publication 3. Köln, Westdeutscher Verlag: Opladen.

Pflanz, M. (1969). Medizinsoziologie. In Handbuch der empirischen
Sozialforschung, Vol. 2 (ed. R. König), pp. 1123-1156. Enke: Stuttgart.

Rawnsley, K. (1984). Psychiatry in jeopardy. British Journal of Psychiatry 145, 573-578.

Ruchman, A. \& Barry, A. (1985). More and more is less and less. The myth of massive psychiatric need. British Journal of Psychiatry 146, $164-168$.

Scadding, J. G. (1967). Diagnosis: the clinician and the computer. Lancet ii, 877-882.

Schneider, K. (1950). Klinische Psychopathologie (3rd edn). Thieme: Stuttgart.

Schneider, K. (1956). Die Beurteilung der Zurechnungsfähigkeit (3rd edn). Thieme: Stuttgart.

Sydenham, T. (1742). Observationes medicare (1676). In The Entire Works of Thomas Sydenham Newly Made English from the Originals (ed. J. Swan). Cave: London.

Szasz, T. S. (1961). The Myth of Mental Illness. Secker \& Warburg: London.

Virchow, R. (1895). Hundert Jahre Allgemeiner Pathologie. August Hirschwald: Berlin. 